\title{
THE GROWTH OPPORTUNITIES FOR SMC?
}

\author{
Jan Bentzen', Erik Strøjer Madsen², Valdemar Smith ${ }^{3}$ \\ Department of Economics, Aarhus School of Business Prismet, Silkeborgvej 2, \\ DK-8000 Aarhus C, Denmark.E-mail:1jb@asb.dk, 22ema@asb.dk, 32vs@asb.dk
}

Received 0603 2006; accepted 28042006

\begin{abstract}
The extensive empirical literature on the validity of Gibrat's law does not in general verify the law as it finds that firms' growth rates are negatively correlated with both firm size and age. However, some studies find that Gibrat's law holds for sub-samples of firms such as large firms or firms belonging to special industries. It has been pointed out that these results are due to the fact that the likelihood of firm survival for natural reasons is positively related to firm size and age. This study uses a relatively large and representative sample of Danish firms to evaluate the validity of Gibrat's law for different kinds of firms over the period 1990 - 2003. In contrast to the majority of earlier studies our analysis corrects for the bias in the estimations by using variables related to the survival of small firms.
\end{abstract}

Keywords: firms, growth opportunities, development.

\section{Introduction}

The high unemployment in Europe over the past thirty years has attracted a lot of political interest in the developments of private companies as an important creator of jobs. One result of this particular focus on employment has been that many countries as well as the EU have designed special measures in their industrial policies to support small and medium sized firms. The policy of supporting small firms seems to presume that they have some disadvantages compared to larger firms and that the policy could compensate such a kind of market failure. However, this presumption of a disadvantage to smaller firms seems to be in conflict with the empirical evidence on firm growth rate. Many studies find no relation at all between firms' growth rates and their size, and those that point to a significant relation find exactly the opposite, e.g. that smaller firms have a higher growth rate than larger firms.

The creation of new firms and the development of existing firms has always been a central topic in economics. Even before the emergence of industrial economics as a research field after the writing of
J. S. Bain on firm performance and industrial structure after the Second World War, economists have stressed the importance of firm size and firm growth. One of the earliest contributions is Gibrat (1931), where a formal model of firm growth and the industrial structure is formulated. In his book Robert Gibrat presents a new economic law: The Law of Proportional Effect.

The law states that the expected increase in firm size is proportionate to its initial size. The economic motivation for this relation is that larger firms have larger growth opportunities than smaller firms as they possess a proportionally bigger market. Consequently, whatever the reason is for an increase or decrease in the market size, larger firms are proportionally more exposed to any chance in market size. Denoting the size of firm $i$ at time $t$ by $X_{i \mathrm{t}}$ and the proportional scale factor by $g_{t}$, the law could be formulated as:

$$
X_{i t}-X_{i t-1}=g_{t} X_{i t-1} .
$$

An implication of this proportionality between firms' absolute growth and their size is that the growth rates 
of firms are independent of their size and equal to the scale factor, and by rearranging equation (1) we therefore have:

$$
\frac{X_{i t}-X_{i t-1}}{X_{i t-1}}=g_{t}
$$

Gibrat uses the law of proportional effect as an assumption and it is furthermore demonstrated that if the firms' growth opportunities were randomly distributed then the distribution of firm size would be skewed and approach a lognormal distribution. Gibrat verified in his book that this prediction was very much in line with the actual distribution of firm size within most industries, and many of the first empirical investigations of Gibrat's law tested the actual firm size distribution against a theoretical statistical distribution. When the law has attracted so much attention during the time, it is probably due to this statistical regularity where the observed industry structure could be the result of solely random external or internal factors determining the growth rate of individual firms.

This paper contributes to the empirical evidence by using a representative sample of all Danish firms. This is contrary to many of the earlier studies which only include manufacturing industries and only large firms. The service industry has been examined in a recent study by Audretsch, Klomp and Thurik (2004) using data from the Dutch service sector. However, they miss data for manufacturing industries and were unable to make a direct comparison between the two kinds of industries. Our data fill this gap and at the same time the data cover a longer period of observation which makes it possible to study more in depth why Gibrat's law fails to be fulfilled in some industries but not in others.

The next section gives a survey of the recent empirical literature on Gibrat's law, section 3 presents the model to be estimated and section 4 includes a description of the data used in the empirical analysis. Section 5 presents the empirical results and the final part concludes.

\section{Recent empirical evidence}

A vast quantity of economic literature deals with firm growth and in particular the empirical validity of Gibrat's law. Over time these studies have become more advanced as econometric methods have developed further and the data bases of firms have increased and cover a broader range of firms and contain more information of each firm. The empirical studies therefore differ widely in econometric method used. A typical specification of the regression analysis to test the law of proportionate effects is as follows:

$$
\Delta x_{t, i}=\beta x_{t-1, i}+\varepsilon_{t, i} .
$$

where $x_{t, i}$ denotes the logarithm to the size of firm, $X_{t, i}$ and $\varepsilon_{t, i}$ is a stochastic term. The model is often estimated as a cross-sectional regression and Gibrat's law holds if the restriction $\beta=0$ is fulfilled. Another group of studies use a dynamic approach to test Gibrat's law by using the following random walk model in the regression specification:

$$
x_{t, i}=\gamma x_{t-1, i}+\varepsilon_{t, i} .
$$

In this formulation firm growth is determined by the stochastic term $\varepsilon_{t, i}$ and the restriction $\gamma=1$ should be fulfilled for the law to hold. However, subtracting $x_{t-1, i}$ on both sides in equation (4) results in an expression like equation (3), i.e $\gamma-1=\beta$. An implication of this formulation is that the growth should be persistent over time for the law to hold. If there is any drift in the growth rate, it would not be independent of the size of the firm and the law would fail.

Sutton (1997), Caves (1998) and Audretsch, Klomp and Thurik (2004) give an excellent survey of the earlier studies. These studies include both small and large firms and represent firms from a large number of countries and they consistently find that the growth rate of firms tends to decrease with increasing firm size and so they do not support Gibrat's law. These results were so consistently strong that Geroski (1995) classified them as a stylised result. However, some of these studies also find some modifications to this result. Thus, two important modifications are that Gibrat's law often holds for specific industries or when only large firms are included in the sample.

One measurement problem in empirical studies is a selection bias in the data and this problem was already pointed out by Mansfield (1962). The problem occurs because firms below the minimum efficient size (MES) have lower probability of surviving as they are less efficient compared to larger firms and, as a result, the firm's survival rate is negatively correlated with its size. When small firms with negative growth rate are forced out of business while large firms with negative growth survive, an upward bias in the growth rate of smaller firms emerges, because only the surviving firms are included in the sample for the succeeding periods. This bias is different in different samples as Mansfield also points out. The bias will 
be less in a cross section analysis using all firms while the bias will increase with the period covered in a panel study only including survival firms.

Many of the recent studies also report a tendency for small firms to grow faster than their larger counterparts. Hart and Oulton (1996) find a negative sizegrowth relationship in a dataset of 87,000 small independent UK firms for the period 1989-93 using both net asset and sales as a measure of size. In a smaller sample of 29,000 UK firms Hart and Oulton (1999) use employees as a measure of size and again find a negative size-growth relationship for firms except for very large firms. Wilson and Morris (2000) examined 430 UK manufacturing and service firms in the period 1991-93 and, using net asset as a size measure, they found that smaller firms had a higher growth rate. In a sample of 400 European banks Wilson and Williams (2000) use total asset and equity as a measure of size in the period 1990-96 and find that small Italian banks grow faster than larger banks while there was no size-growth relationship for banks in the UK, Germany and France. Blonigen and Tomlin (2001) use number of employees as a size measure for a sample of Japanese owned manufacturing plants in the US and they also find that small plants have a higher growth rate.

However, Audretsch, Klomp and Thurik (2004) find no size-growth relationship in a study of 1,170 Dutch service firms for the period 1987-91. They argue that this result may be due to the low entry barriers in the service sector as compared to the manufacturing sector where all the existing empirical studies at that time were carried out. In a 30-year study of 147 large UK quoted firms Geroski (2003) finds little or no evidence of any relation between growth and firm size.

The latter group of studies suggest that Gibrat's law will most likely hold when sufficient effort has been made to take care of the sample selection bias and instead of examining growth rates of different firms with different sizes attention should be paid to the economic reasons why the law failed to be fulfilled in some industries.

\section{The empirical model}

In this paper we use the dynamic specification of the regression models as originally suggested by Chesher (1979) to test Gibrat's law as to whether firm growth rates are independent of firm size. The empirical specification which is also used by Audretsch et al. (2004) is the following:

$$
Z_{t, i}=\beta Z_{t-1, i}+\varepsilon_{t, i}
$$

where $Z_{t, i}$ denotes the deviation of the logarithm to the firm size from the mean of the log size of companies in the various industries which are included in the analysis below. If the estimate of $\beta$ turns out to be unity this can be seen as evidence in favour of Gibrat's Law or 'The Law of Proportionate Effect', which implies that 'a change in the variate at any step of the process is a random proportion of the previous value of the variate', see Chesher (1979). Chesher (1979) also demonstrates that additional to an estimate of $\beta$ equal to unity the residuals from (1) must be distributed independently over time. Serial correlation in $\varepsilon_{t, i}$ from equation (1) will result in inconsistent estimates of $\beta$. As a result 'the proportionate effect' will not be independent of the previous value of firm size.

Therefore, the empirical specification is extended to cope with autocorrelation in the residuals. The first order autoregressive process is given by (6); see Chesher (1979) or Audretsch et al. (2004) for further details:

$$
\begin{gathered}
\varepsilon_{t, i}=\rho \varepsilon_{t-1, i}+v_{t, i}, \\
Z_{t, i}=(\beta+\rho) Z_{t-1, i}+(-\beta \rho) Z_{t-2, i}+v_{t, i},
\end{gathered}
$$

when $(\beta, \rho)$ is equal to $(1,0)$ Gibrat's Law is considered to be fulfilled because $\beta$ is equal to unity and firm growth rates are not correlated with the values from the preceding period. The parameters in equation (7) can be estimated (all estimations and tests are calculated by using RATS) by using a non-linear iteration procedure. However, the results do not appear sensitive to the choice of estimation procedure. Testing for the values of $\hat{\beta}$ and $\hat{\rho}$ is performed as a joint test for both parameters fulfilling the (1,0)-restriction where the test-statistic is distributed as $\chi^{2}$ with two degrees of freedom.

To deal with the sample selection bias as noted above the estimation model in equation (7) has been run for each separate quartile of firm size and the test statistics for $(\beta, \rho)$-restriction are reported in table 3 where firm size is measured with turnover.

\section{Data}

The data used in this paper comes from the private consultant company, Købmandsstandens Oplysningsbureau. The record for each firm includes 
account information from its annual report supplemented with specific firm information collected from a telephone interview of each firm at least once a year. Furthermore, as the data set includes economic information on all Danish companies the industry aggregates have been calculated on the basis of this data for each year in the analysing period 1990-2003.

In this paper we test the validity of Gibrat's Law by using a dynamic specification and in order to correct for autocorrelation in the econometric model a balanced panel is constructed. Thus, it is required that each firm must have been economically active over the whole period in the way that the firm has sent an annual report to the authorities. Furthermore it is demanded that the firm has reported information on its total employment, total turnover and total capital in each year and, therefore, the final data set contains a complete record for each panel firm.

In total the data base includes information on 626 firms for the period 1990-2003. Table 1 presents summary statistics for all industries; see the appendix for similar information for each sub-industry.

The average number of employees is around 100, which shows that Danish firms are relatively small. Average net turnover is approximately 220 mill. DKK and the turnover per employee is about 1.5 mill. DKK. It is also seen that employment has decreased, whereas net turnover has increased, indicating productivity gains or a higher degree of specialisation between the firms with more outsourcing.

To deal with the sample selection bias in the empirical part of the paper, the data set is divided into 4 groups according to quartiles for firm size in 1990. In the first group the $25 \%$ smallest firms (in 1990 by turnover), the second group is the next quartile (by turnover) etc. Table 2 gives summary statistics for these four groups of firms. The table shows that the average size of Danish firms is relatively small (note that the figures relate to 1990). Even among the firms above average but below the upper quartile the average turnover is below 36 mill. DKK and the average turnover in the lowest quartile is only 1.2 mill. DKK in 1990.

Table 2 also shows that the smallest firms belonging to the lowest quartile have the highest average growth in turnover per year over the period from 1990 to

Table 1. Summary statistics for all variables included in the data set, 1990

\begin{tabular}{|l|r|r|}
\hline \multicolumn{1}{|c|}{ All industries } & Mean & Standard deviation \\
\hline Number of employees & 94.39 & 381.03 \\
\hline Net turnover (1000 DKK) & $218,795.39$ & $1,690,873.95$ \\
\hline Total assets (1000 DKK) & $1,052,325.07$ & $16,380,735.87$ \\
\hline Turnover per employee & $1,559.70$ & $2,995.01$ \\
\hline Capital sales ratio (total assets/sales) & 2.57 & 10.64 \\
\hline Annual Growth, 1990-2003: & & 18.69 \\
\hline Employment & -2.19 & 15.41 \\
\hline Net turnover & 1.76 & 9.24 \\
\hline Total assets & 3.96 & 626 \\
\hline Number of firms & & \\
\hline 6.85 DK & & \\
\hline
\end{tabular}

$6.85 \mathrm{DKK}=1 \$$

Table 2. Mean statistics by firm size for some variables

\begin{tabular}{|l|c|c|c|c|}
\hline Firm size: & Lowest Quartile & Second Quartile & Third Quartile & Upper Quartile \\
\hline $\begin{array}{l}\text { Net Turnover } \\
1000 \text { DKK, } 1990\end{array}$ & 1,201 & 5,279 & 35,903 & 830,221 \\
\hline $\begin{array}{l}\text { Growth in turnover } \\
\text { 1990-2003, p.a. }\end{array}$ & $3.8 \%$ & $-1.8 \%$ & 3.19 & $1.9 \%$ \\
\hline Capital/sales ratio & 5.66 & $1.8 \%$ & 1.70 & 1.15 \\
\hline
\end{tabular}


2003. Moreover the growth rate of this group is twice as high as the growth rate of the largest firms' turnover. The average statistics on the capital-sales ratio reveals that the smaller firms use a lot more capital per DKK in turnover, in fact precisely five times more capital. This indicates that smaller firms are less capital efficient and may have higher costs than the larger firms.

\section{Results}

The estimated parameters of $\beta$ and $\rho$ from the dynamic specification of the regression model (7) are listed in table 3 for the different industries. As a size measure we use the firms' turnover and the estimates show a serious negative autocorrelation of firm growth rate within the industries of other manufacturing and business services. To take care of this econometric problems we use a $\chi^{2}$-test to verify that the joint restriction of persistent growth rats and no autocorrelation holds or: $(\beta, \rho)$ is equal to $(1,0)$.

The $\chi^{2}$-test shows a rejection of the restriction for 5 of the 9 industries at a five per cent level of significance. The other four industries where Gibrat's law seems to hold are the industries of wholesale, retail, hotel and restaurants and finance. These results support the findings of Audretsch et al. (2004) for the Dutch service sector which also fulfil Gibrat's law. However, they only examine the industries for the hotel, restaurant, camping and hospitality sectors. Our results verify that Gibrat's law holds for the whole service sector except for business services.

Furthermore, Audretsch et al. (2004) expect that their result would be different for the manufacturing sector due to high entry barriers in this sector and, for that reason, a larger sample selection bias. But their data do not include the manufacturing industry and they do not prove this hypothesis. Our estimations verify that Gibrat's law does not hold for the manufacturing sector and surprisingly not for the construction industry either.

To examine where high entry barriers within the manufacturing industries create a sample selection bias in the estimations the sample has been split into 4 subsamples, i.e. quartiles defined by firm size. If smallfirm survival bias is prevalent, then acceptance of Gibrats law should be dependent on which size class

Table 3. Test statistics for $\beta, \rho$ and the $(\beta, \rho)$-restriction in the different industries

\begin{tabular}{|l|c|c|c|}
\hline \multicolumn{1}{|c|}{ Industries } & $\beta$ & $\rho$ & $\chi^{2}$-test for $(\beta, \rho)$ \\
\hline $\begin{array}{l}\text { Basic metals and } \\
\text { machinery }\end{array}$ & 1.012 & $(0.003)$ & 0.023 \\
\hline Other manufacturing & $(0.082)$ & $26.26^{*}$ & -0.233 \\
& 1.007 & $(0.003)$ & $(0.00)$ \\
\hline Construction & $1.047)$ & $27.22^{*}$ & -0.274 \\
& $(0.124)$ & $(0.004)$ & $-0.00)$ \\
\hline Wholesale industry & 1.004 & $22.68^{*}$ & $(0.34)$ \\
& $(0.054)$ & $(0.006)$ & -0.120 \\
\hline Retail industry & 1.004 & $(0.006)$ & $0.05)$ \\
& $(0.127)$ & 5.82 & $0.13)$ \\
\hline Hotel and restaurants & 1.020 & $(0.010)$ & 0.144 \\
& $(0.095)$ & 4.10 & $(0.02)$ \\
\hline Transport and & 0.983 & $(0.007)$ & -0.021 \\
telecommunication & $(0.101)$ & $8.18^{*}$ & $(0.41)$ \\
\hline Finance and rental services & 1.003 & $(0.003)$ & $\left(0.05^{*}\right.$ \\
& $(0.053)$ & 1.79 & $(0.160$ \\
\hline
\end{tabular}

Notes: Standard errors reported in parentheses. For the $\chi^{2}$-test of the $(\beta, \rho)$-restriction p-values are reported in parentheses where $*$ indicates a rejection of the restriction at (least) the five per cent level of significance. Numbers of observations in the different industries are reported in the appendix. 
Table 4. Test statistics for $\beta$ in the different quartile of firm size

\begin{tabular}{|c|c|c|c|c|}
\hline Industries & Lowest Quartile & Second Quartile & Third Quartile & Upper Quartile \\
\hline \multirow{2}{*}{$\begin{array}{l}\text { Basic metals and } \\
\text { machinery }\end{array}$} & $19.84^{*}$ & $(0.00)$ & 2.35 & $(0.31)$ \\
\hline & $7.20^{*}$ & $(0.03)$ & 1.06 & $(0.59)$ \\
\hline \multirow[t]{2}{*}{ Other manufacturing } & $15.45^{*}$ & $(0.00)$ & $13.48^{*}$ & $(0.00)$ \\
\hline & $8.77^{*}$ & $(0.01)$ & 5.75 & $(0.06)$ \\
\hline \multirow[t]{2}{*}{ Construction } & $9.52 *$ & $(0.00)$ & $27.67^{*}$ & $(0.00)$ \\
\hline & $22.28^{*}$ & $(0.00)$ & 1.10 & $(0.58)$ \\
\hline \multirow[t]{2}{*}{ Wholesale industry } & 0.13 & $(0.94)$ & $12.63^{*}$ & $(0.00)$ \\
\hline & 2.58 & $(0.29)$ & 0.84 & $(0.66)$ \\
\hline \multirow[t]{2}{*}{ Retail industry } & 2.79 & $(0.25)$ & $7.92 *$ & $(0.00)$ \\
\hline & $8.47^{*}$ & $(0.01)$ & 2.76 & $(0.25)$ \\
\hline Hotel and restaurants & \multicolumn{4}{|c|}{ Missing } \\
\hline \multirow{2}{*}{$\begin{array}{l}\text { Transport and } \\
\text { telecommunication }\end{array}$} & $9.17^{*}$ & $(0.01)$ & $9.34 *$ & $(0.01)$ \\
\hline & 1.39 & $(0.50)$ & 1.69 & $(0.43)$ \\
\hline \multirow{2}{*}{$\begin{array}{l}\text { Finance and rental } \\
\text { services }\end{array}$} & 3.70 & $(0.16$ & 2.45 & $(0.29)$ \\
\hline & 5.92 & $(0.05)$ & 1.73 & $(0.42)$ \\
\hline \multirow{2}{*}{$\begin{array}{l}\text { Business services and } \\
\text { Other ser. }\end{array}$} & 2.68 & $(0.26)$ & $10.23^{*}$ & $(0.01)$ \\
\hline & $11.84^{*}$ & $(0.00)$ & 4.95 & $(0.08)$ \\
\hline
\end{tabular}

Notes: For the $\chi^{2}$-test of the $(\beta, \rho)$-restriction $p$-values are reported in parentheses where $*$ indicates a rejection of the restriction at (least) the five per cent level of significance. Numbers of observations in the different industries are reported in the appendix. Only 14 observations exist in hotels and restaurants and for the whole industry Gibrat's Law survived with the $\chi^{2}$-test of: $4.10(0.13)$.

the firms belong to. Thus Gibrats law is mainly expected to hold in the quartiles with the larger firms. Table 4 shows the estimation results.

The values of the $\chi^{2}$-test for the $(\beta, \rho)$-restriction seem to confirm the hypothesis of some selection bias in the manufacturing industries. Thus, $\chi^{2}$-values are not significant at the $5 \%$ level for any of the industries in the upper quartile with the biggest firm. This indicates acceptance of Gibrat's law of proportional effect for the largest firms. Note that it also holds for firms in the hotel and restaurant industry. Thus it is a general result from the table that the firms' growth rates are independent of firm size for large firms belonging to the upper quartile.

For firms belonging to the first 3 quartiles the results are not that different. Gibrat's Law holds for 4 industries in quartile 1 , for only 2 industries in quartile 2 and 3 industries in quartile 3 . The main lesson to be learned from these results is that it is not only among the smallest firms that Gibrat's law fails but also among the majority of firms as it only holds for the largest quartiles. This result is in accordance with a'priori expectations because Danish firms are fairly small on average and only the largest firms have growth big enough to produce past the MES level. This interpretation is verified by the figures for the capital sales ratio in table 2 where the largest firms in quartile 4 have a capital sales ratio that is about $50 \%$ below the level for firms belonging to quartile 2 and 3 . This capital disadvantage of firms not belonging to the upper quartile could reduce the survival rate for firms with a low growth rate and thereby kill Gibrat's law with a sample selection bias.

Table 4 also shows some differences between the industries. The law holds for the hotel and restaurant industry, finance and rental services and the majority of firms in the wholesale industry. It is not surprising that Gibrat's law is rejected for manufacturing industries and transportation- and telecommunication-sector where large barriers to entry most likely exist. However, it is surprising that it fails to hold in the construction industry.

\section{Conclusion}

Gibrat's law of the proportional effect states that the growth rates of firms are independent of their size. The majority of earlier empirical studies of Gibrat's law do 
not support it. It is mainly found that the growth rate of firms tends to decrease with increasing firm size. However, some studies find results that to some extent differ from the general result.

This study uses a relatively large and representative sample of Danish firms to evaluate Gibrat's law of the proportional effect for different firm size groups over the period 1990 to 2003. The main result found is that Gibrat's law holds for the whole service sector except business service and this result supports the finding in I Dutch study. However, the law fails to hold within the manufacturing and construction industries when the test includes all firms, i.e. also smaller ones with an output below the minimum efficient scale.

Focussing on potential small-firm survival bias our study demonstrates that Gibrat's law is supported also for the manufacturing and construction industries for the largest firms, i.e. firms included in the upper quartile of firms sizes. For the other firms sizes the results are mixed, but in many cases the law does not hold and the growth rate of firms tends to decrease with firm size. The result that the law only holds for the largest firms could be a result of the relatively small size of Danish firms compared with other countries. Therefore it would be of interest if similar tests could be performed for comparable firms in other countries.

\section{References}

Gibrat, R. (1931). Les inégalités économiques; applications: aux inégalités des richesses, à la concentration des enterprises, aux populations des villes, aux statistiques des familles, etc., d'une loi nouvelle, la loi de l'effet proportionnel. Paris: Librairie du Recueil Sirey.

Audretsch, D. B.; Klomp, L. and Thurik, A. R. (2004). Gibrat's Law: are the services different? Review of Industrial Organization, Vol 24, No 3, p. 301-324.

Sutton, J. Gibrat's Legacy. (1997). Journal of Economic Literature, Vol 35, p. 40-59.

Caves, R. E. (1998). Industrial Organization and New Findings on the Turnover and Mobility of Firms. Journal of Economic Literature, Vol 36, p. 1947-1982.

Geroski, P. A. (1995). What Do We Know About Entry? International Journal of Industrial Organization, Vol 13, p. 421-440.

Mansfield, E. F. (1962). Entry, Innovation, and the Growth of Firms. American Economic Review, Vol 52, p. 10231051.

Hart, P. E. and Oulton, N. (1996). The size and growth of firms. Economic Journal, Vol 106, p. 1242-1252.

Hart, P. E. and Oulton, N. (1999). Gibrat, Galton and job generation. International Journal of the Economics of Business, Vol 6, p. 149-164.
Wilson, J. O. S. and Morris, J. E. (2000). The size and growth of UK manufacturing and service firms. Service Industries Journal, Vol 20, p. 25-38.

Wilson, J. O. S. and Williams, J. M. (2000). The size and growth of banks: evidence from four European countries. Applied Economics, Vol 32, p. 1101-1109.

Blonigen, B. A. and Tomlin, K. (2001). Size and growth of Japanese plants in the United States. International Journal of Industrial Organization, Vol 19, p. 931-952.

Geroski, P. A. (2003). The Evolution of New Markets. Oxford University Press.

Chesher, A. (1979). Testing The Law of Proportionate Effect. The Journal of Industrial Economics, Vol 27, No 4, p. 403-411. 